\title{
Small procedural differences matter: Conceptual and direct replication attempts of the communication-intervention effect on infants' false-belief ascriptions
}

\author{
Cornelia Schulze $e^{1,2,3} \&$ David Buttelmann ${ }^{3,4}$ \\ ${ }^{1}$ Department of Educational Psychology, Faculty of Education, University of Leipzig \\ ${ }^{2}$ Leipzig Research Center for Early Child Development, Leipzig, Germany \\ ${ }^{3}$ University of Erfurt, Germany \\ ${ }^{4}$ Department of Developmental Psychology, Institute of Psychology, University of Bern
}

Author notes:

Cornelia Schulze (iD https://orcid.org/0000-0001-9151-4792

David Buttelmann (D) https://orcid.org/0000-0002-0915-7114

Correspondence concerning this article should be addressed to Cornelia Schulze, Department of Educational Psychology, Faculty of Education, University of Leipzig, Marschnerstraße 31, D-04109 Leipzig, Germany. Email: cornelia.schulze@uni-leipzig.de

Declarations of interest: none

Funding resources: This research was funded by the Postdoctoral Fellowship of the University of Erfurt awarded to the first author.

\section{Acknowledgements:}

The authors thank Andy Schieler for building the apparatus, Gudrun Schaarschmidt, Martina Greiner, and Julia Prein for help with data collection, Nadin Helbing for organizational help, and Leony Bals, Helena Goerigk, and Elisabeth Schulze for assistance with coding. 


\begin{abstract}
The current replication crisis in experimental psychology has also called into question findings regarding infants' early false-belief understanding. It is, however, debated whether non-replications might be due procedural differences between replication attempts and original studies. The current set of studies aimed to shed light on this question by trying to replicate a violation-of-expectation study by Song, Onishi, Baillargeon and Fisher (2008). This task seemed especially important since it addressed not only the question whether or not infants hold false-belief assumptions but whether they update them given informative verbal input. Studies $1 \mathrm{a}$ and $1 \mathrm{~b}$ failed to replicate the original findings conceptually. Study $2-$ which followed the original procedure more closely - replicated the original finding regarding informative interventions. However, the same effect was found with so-called uninformative statements. We argue that theoretically, children should update their expectations when communication takes place and that other, more subtle features of a task might influence infants' performance. Overall, the current set of studies emphasizes that direct replication attempts for single studies need to follow the original design and procedure as closely as possible.
\end{abstract}

Keywords: replication crisis; Theory of Mind; infants; early communication 


\section{Introduction}

Over the past 15 years, findings supporting an assumption of an implicit false-belief understanding (FBU) in infants have accumulated from infant studies using a variety of tasks (e.g., Scott \& Baillargeon, 2017 for a review). In recent years, however, the replication crisis in experimental psychology (Maxwell et al., 2015) has also called into question findings regarding infants' early FBU. Specifically, in a dataset consisting of (published and unpublished) self-reported replications and non-replications, Kulke and Rakoczy (2018) showed that a series of implicit infant false-belief tasks using different paradigms (such as anticipatory looking, violation of expectation and interactive tasks) were not or only sometimes replicable (see also Kulke, Reiß, et al., 2018; Kulke, von Duhn, et al., 2018; for an overview of methodological concerns see Poulin-Dubois et al., 2018). However, while authors who failed to replicate original findings often did not discriminate between conceptual replications (i.e., those trying to replicate the phenomenon using [slightly] different procedures) and direct replications (i.e., those following the exact original protocol), authors of original publications and others pointed out that procedural differences between replication studies and original studies might explain failures to replicate (Baillargeon et al., 2018; Kidd \& Castano, 2017; Rubio-Fernández, 2018).

To which extend infants possess an understanding of others' false beliefs is a very important theoretical question because inferring what is on others' minds is a task that we - as adults - do constantly in order to explain or predict their actions. Thus, the question when in ontogeny children start to analyze the world around them not only in terms of observable features but also based on inferred mental processes is hotly debated in the developmental and philosophical literature (e.g., Apperly \& Butterfill, 2009; Carruthers, 2013). The majority of previous replication studies focused on infants' false-belief understanding in tasks in which participants looked at scenes or locations, or helped according to whether or not they 
ascribed the protagonist a false belief (e.g., D. Buttelmann et al., 2009; Onishi \& Baillargeon, 2005; Southgate et al., 2007). However, a smaller body of research on infant FBU investigated how infants update a belief they ascribed to a protagonist due to changes in the environment or because the protagonist gained information that corrected his or her false belief. Studies like these are important because they demonstrate not only that infants ascribe false beliefs to others but rather that they do so flexibly and adapt to new circumstances. One prominent example in this regard is a study by Song, Onishi, Baillargeon, and Fisher (2008). These authors investigated whether infants understood how communication between an assistant and an agent changes the agent's mental states (see also Jin et al., 2019; Tauzin \& Gergely, 2018). The ability to understand that communication affects mental states is highly relevant in real life given that communication is one of the main tools to inform others about observable and non-observable (i.e., internal) facts. Song and colleagues showed that infants' FBU is flexible enough to evaluate information provided for an agent with a false belief and to reconsider their assumptions about the agent's action in the light of this information (see also Jin et al., 2019).

The aim of the current study was to replicate the study of Song and colleagues in a European sample. We further examined to role of specific components of the procedure in children's assumption about others' mental states when communication took place. Study 1a tried to replicate the original study conceptually using informative and uninformative statements as an intervention that should (in the case of informative statements) result in changes in the infants' expectations regarding the agent's actions. Study $1 \mathrm{~b}$ tested infants' updating of belief ascriptions when the informative statement was made even more salient. That is, this study combined the verbal informative intervention with an unambiguous pointing gesture. Study 2 is a direct replication of the Song et al. study, following the original study's procedure even more closely by introducing a delay between the phases within a trial. 
For each study, we expected to replicate the original study, that is, that infants would update their belief-based expectations when the agent heard informative statements.

\section{Study 1a}

\subsection{Method}

\subsubsection{Participants}

Fifty-six 18-month-old German-speaking children participated in this study. The children's mean age was 18 months; 24 days (range: 17;24 - 19;29, 23 boys and 33 girls). Eighteen additional children were tested but had to be excluded from the final sample due to equipment failure $(n=4)$, parental interference $(n=2)$, because they did not see the agent put the ball in the box in at least one of the two relevant familiarization phases (i.e. familiarization-criterion, $n=2$ ), or because they did not reach the minimum looking-time criterion in the test phase's paused scene ( $n=9$, see procedure). This study, as well as the following ones, was conducted in accordance with the ethical standards laid down in the Declaration of Helsinki and the standards of the local ethics committee of the University of [blinded for review]. The children's parents had previously agreed to their children participating in studies on child development in a mid-sized German city. In addition to their general agreement, parents signed a consent form for participating at the current study prior to testing. Each infant received a toy and a certificate as gratification.

The current project was part of a research project investigating the role of communication in belief ascription. Further conditions focusing on the role of the social context in the Song et al. (2008) original study were run and are reported in a separate publication (for a preprint see Schulze \& Buttelmann, 2020).

\subsubsection{Materials and set-up}

The materials and set-up of the current study matched that of Song et al. (2008) as closely as possible. Thus, the children sat in front of a stage-like apparatus across the agent, 
with the assistant sitting to their right (see Figure 1). The apparatus' stage area was approximately $100 \mathrm{~cm}$ wide, $60 \mathrm{~cm}$ deep, and $100 \mathrm{~cm}$ high, and curtains could be closed in front of the agent and the assistant. The agent sat on a chair and wore a blue shirt and ivory visor that hid her eyes from the child's view. The assistant sat on a chair and wore a green shirt and a light-green visor. On either side of the apparatus stood a frame made from grey card board (160 cm high, $80 \mathrm{~cm}$ wide) that blocked the child's view of the room and of the assistant.

\section{Figure 1.}

Illustration of the study set-up.

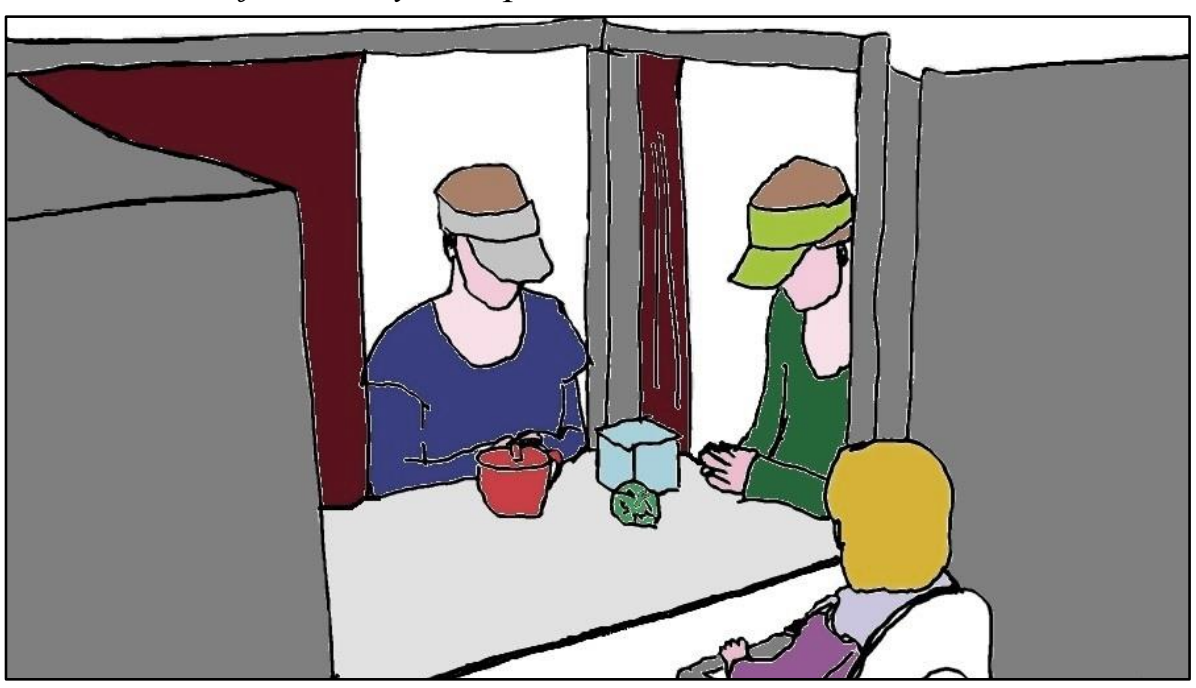

A box $(10 \times 10 \times 10 \mathrm{~cm})$ with a lid (both light-blue with a white pattern) and a cup (10 $\mathrm{cm}$ tall, $10 \mathrm{~cm}$ in diameter at the top) with a lid (both red) stood approximately $40 \mathrm{~cm}$ away from the child, centered and $15 \mathrm{~cm}$ apart from each other. In the middle between the box and the cup and about $5 \mathrm{~cm}$ in front of them lay a green plastic koosh ball $(5 \mathrm{~cm}$ in diameter).

All sessions were videotaped from three different angles.

\subsubsection{Design}

As in Song et al.'s study, the children saw one trial consisting of three familiarization phases (in which the agent placed the ball in the box), one belief induction phase (in which 
the assistant moved the ball from the box to the cup), one intervention phase (that differed according to condition, see below) and one test phase in which the agent reached either into the cup (cup event) or into the box (box event). The children's expectations about the agent's actions in the test phase were manipulated in two between-subjects conditions: In the Informative-Intervention Condition, the assistant told the agent that "The ball is in the cup", whereas in the Uninformative-Intervention Condition the assistant told the agent "I like the cup". The position of both containers was counterbalanced between children. Children were randomly assigned to one of the two conditions and one of two test events (see below).

\subsubsection{Procedure}

Warm-up. After a warm-up phase, the child, her parent, the agent and the assistant moved to the testing room and took seats at the table with the apparatus. At this point, all curtains were closed, and the box, the cup and the koosh ball were laying on the stage, visible to participants. The agent and the assistant took their seats behind their respective windows and opened the curtains simultaneously. They then interlaced their fingers and looked at a neutral point between the box, the cup and the ball (note that the eyes of the experimenters were not visible to the child).

$\mathbf{1}^{\text {st }}$ familiarization phase-initial scene. The agent took the ball (either with her left hand if the box stood to her right or with her right hand if the box stood to her left) and moved it to a position $20 \mathrm{~cm}$ above the stage floor, centered between both containers (added together approx. $2 \mathrm{sec})$, and rotated it four times $(4 \mathrm{sec})$. The agent's free hand than opened the lid of the box $(2 \mathrm{sec})$. She then placed the ball inside the box $(2 \mathrm{sec})$, moved her hand back to the starting position $(1 \mathrm{sec})$, closed the lid $(2 \mathrm{sec})$ and moved her other hand to their interlaced position in front of her $(1 \mathrm{sec})$. During the initial scene, the agent looked towards the ball or, when the ball was inside the box, to the box; the assistant followed the agent's movements with her eyes. When the agent's hands reached their starting position, both agents 
looked at the neutral point between the box, the cup and the ball. The initial scene of this phase lasted about 14 seconds.

$1^{\text {st }}$ familiarization phase-paused scene. A paused scene followed which ended when the child (1) had looked at the scene for at least 2 cumulative seconds and looked away for 2 consecutive seconds or (2) had looked at the scene for 60 seconds without looking away for 2 consecutive seconds. Then the assistant signaled to the agent to proceed with the next phase.

$2^{\text {nd }}$ familiarization phase - initial scene. The agent opened the lid of the box with the hand next to the box $(2 \mathrm{sec})$ and held this lid in its open position for the whole initial scene of this phase. She then grasped the ball inside the box with her other hand $(1 \mathrm{sec})$, moved the ball to a position $20 \mathrm{~cm}$ above the stage floor, centered between both containers $(1 \mathrm{sec})$, and rotated it four times $(4 \mathrm{sec})$. She then placed the ball back inside the box $(2 \mathrm{sec})$, moved her hand back to the starting position $(1 \mathrm{sec})$, closed the lid $(2 \mathrm{sec})$ and moved her other hand to their interlaced position in front of her $(1 \mathrm{sec})$. During the initial scene, the agent looked towards the ball or, when the ball was inside the box, to the box; the assistant followed the agent's movements with her eyes. When the agent's hands reached the starting position, both agents looked at the neutral point between box and cup. The initial scene of this phase lasted about 14 seconds.

$2^{\text {nd }}$ familiarization phase-paused scene. A paused scene followed which ended when the child (1) had looked at the scene for at least 2 cumulative seconds and looked away for 2 consecutive seconds or (2) had looked at the scene for 60 seconds without looking away for 2 consecutive seconds. Then the assistant signaled to the agent to proceed with the next phase.

$3^{\text {rd }}$ familiarization phase-initial scene. The agent opened the lid of the box with the hand next to the box $(2 \mathrm{sec})$ and held the lid in this open position for the whole initial scene of this phase. She then grasped the ball inside the box with her other hand (1 sec). During the 
initial scene, the agent looked towards the box, the assistant followed the agent's movements with her eyes. The initial scene of this third familiarization phase lasted about 3 seconds.

$3^{\text {rd }}$ familiarization phase-paused scene. A paused scene followed which ended when the child (1) had looked at the scene for at least 2 cumulative seconds and looked away for 2 consecutive seconds or (2) had looked at the scene for 60 seconds without looking away for 2 consecutive seconds. Then the assistant signaled to the agent to proceed with the next phase. The agent closed the lid of the box, reclined in her chair and closed the curtain in front of her. The assistant looked at the neutral point between box and cup.

Belief induction phase - initial scene. The assistant looked towards the box and moved her right hand towards the lid of the box $(1 \mathrm{sec})$, opened it $(1 \mathrm{sec})$, moved her left hand towards the box, grasped the ball inside the box $(1 \mathrm{sec})$, removed it from the box and moved it to a position centered between both containers and $20 \mathrm{~cm}$ above the stage floor (1 sec). She then closed the lid of the box with her right hand (1 sec), moved her right hand towards the cup $(1 \mathrm{sec})$, opened the lid of the cup by holding the lid about $10 \mathrm{~cm}$ above the cup ( $1 \mathrm{sec})$, placed the ball in the cup $(2 \mathrm{sec})$, moved her left hand back to its starting point (1 sec), closed the lid of the cup ( $1 \mathrm{sec})$, moved her right hand back to its starting position, and looked at the neutral point between both containers $(1 \mathrm{sec})$. The initial scene of the belief induction phase lasted 12 seconds.

Belief induction phase-paused scene. A paused scene followed which ended when the child (1) had looked at the scene for at least 3 cumulative seconds and looked away for 2 consecutive seconds or (2) had looked for 40 seconds without looking away for 2 consecutive seconds. Then the assistant signaled to the agent to proceed with the next phase. The agent then opened her curtain, interlaced her fingers in front of her and looked at the neutral point between the containers.

Intervention phase. The agent and the assistant simultaneously raised their heads and 
looked at each other $(1 \mathrm{sec})$. What followed differed according to condition: In the Informative-Intervention Condition, the assistant said the German equivalent of "The ball is in the cup" ("der BALL IST IN DER TASse"; 2 sec, capital letters mark emphasized syllables), paused (1 sec), and repeated the sentence (2 sec). In the UninformativeIntervention Condition, the assistant said the German equivalent of "I like the cup" ("ich MAG DIE TASse"; 2 sec, capital letters mark emphasized syllables), paused (1 sec), and repeated the sentence $(2 \mathrm{sec})$.

After the communication intervention, both agents then looked back at the neutral point between both containers $(1 \mathrm{sec})$. The assistant then reclined in her chair and closed the curtain in front of her. Then, the agent proceeded with the test phase in which the child saw either a box event or a cup event (between subjects).

Test phase - initial scene: box event. The agent moved her hand next to the box towards the lid of the box $(1 \mathrm{sec})$, opened it $(1 \mathrm{sec})$ and reached inside the box with her other hand $(1 \mathrm{sec})$. She then held this position during the paused scene that followed.

Test phase - initial scene: cup event. The agent moved her hand next to the cup towards the lid of the cup ( $1 \mathrm{sec})$, opened it by lifting it about $9 \mathrm{~cm}$ above the cup $(1 \mathrm{sec})$ and reached inside the cup with her other hand $(1 \mathrm{sec})$. She then held this position during the paused scene that followed.

Test phase-paused scene. Children's looking times towards the objects and the agent were measured until the child (1) had looked at the scene for at least 5 cumulative seconds and looked away for 2 consecutive seconds or (2) had looked for 60 seconds without looking away for 2 consecutive seconds.

\subsubsection{Coding and reliability}

Since all sessions were videotaped, children's looking times were coded in a finegrained way. Using ELAN (http://tla.mpi.nl/tools/tla-tools/elan/) we coded children's looking 
times in 40-ms intervals frame by frame. An independent, blind coder coded a random sample of 10 children (18\% of the sample). As described in Song and colleagues (2008), we divided the paused scenes of the familiarization and test phases into 100-ms intervals to determine whether both coders agreed that the child was or was not looking at the event. Inter-coder agreement was $92.7 \%$.

Children were excluded from analyses when they had not seen the agent put the ball in the box in at least one of the two relevant familiarization phases (i.e. familiarizationcriterion) $(n=2)$ or when they did not reach the minimum looking-time of 5 seconds in the test phase's paused scene (i.e. test-criterion) $(n=9)$.

\subsection{Results and Discussion}

Preliminary analyses revealed that the children were very attentive throughout the study, as they looked at the actions performed in the initial scenes of all phases on average between $84 \%$ and $98 \%$ of the duration of these scenes (see Table 1).

\section{Table 1.}

Children's mean looking times at the initial scenes of each phase and mean durations of these scenes in seconds in Study la. Standard deviations in parentheses.

\begin{tabular}{lccc}
\hline & Looking Time & Duration & Percent \\
\hline $1^{\text {st }}$ Familiarization Phase & $13.9(1.2)$ & $14.2(1.0)$ & $97.5(5.0)$ \\
\hline $2^{\text {nd }}$ Familiarization Phase & $14.3(1.6)$ & $15.0(1.2)$ & $95.9(8.5)$ \\
\hline $3^{\text {rd }}$ Familiarization Phase & $2.8(0.7)$ & $3.4(1.0)$ & $84.0(26.0)$ \\
\hline Belief Induction Phase & $12.4(0.7)$ & $12.6(0.9)$ & $98.2(3.7)$ \\
\hline Intervention Phase & $6.7(0.9)$ & $6.9(0.9)$ & $97.2(6.0)$ \\
\hline Test Phase & $2.5(0.7)$ & $2.8(0.5)$ & $90.0(23.8)$ \\
\hline
\end{tabular}

To test whether the children in both conditions and events looked equally long during the paused scene of the familiarization phases, we averaged the children's looking times at the paused scenes of the familiarization phases and ran a 2 (condition) $\times 2$ (event) ANOVA. There were no significant effects $($ all $F(3,52)<.1 .074$, all $p>.31)$. To test whether the children in both conditions and events looked equally long during the paused scene of the 
belief-induction phase, we ran a 2 (condition) x 2 (event) ANOVA. There were also no significant effects $($ all $F(3,52)<2.397$, all $p>.13)$.

Analyses of the test phase-paused scene. For our main statistical analyses, the dependent variable was children's looking time at the box event or the cup event in the paused scene of the test phase. A 2 (condition) x 2 (event) ANOVA revealed no significant effects (all $F(3,52)<.130$, all $p>.72$, see Table 2$)$.

\section{Table 2.}

Children's mean looking times (and standard deviations) in seconds at the test phase's paused scene of Study la across conditions and events.

\begin{tabular}{ccc}
\hline & Box Event & Cup Event \\
\hline Informative-Intervention Cond. & $8.5(2.5)$ & $8.7(4.3)$ \\
\hline Uninformative-Intervention Cond. & $8.2(2.3)$ & $8.4(3.0)$ \\
\hline
\end{tabular}

In this study, we failed to replicate the study by Song et al. (2008). In the original study, children in the Informative-Intervention Condition expected the agent to search the object in the cup (and thus looked longer at the box event) while children in the Uninformative-Intervention Condition expected the agent to search in the box (longer looking times at the cup event). However, in the current study children did not differentiate between both test events or both conditions. Although the procedure followed the original study, we were wondering whether the communicative act of informing the agent about the toy's new location was not strong enough. Thus, in order to replicate the original finding in the Informative-Intervention Condition (which seemed the most straight-forward way to test whether communication alters infants' expectation about the agents' actions), we ran the Informative-Intervention Condition again with another sample of children in Study 1b. We tried to help the children to understand the content of the informative communication by adding another communicative cue, namely, pointing. Pointing at the location containing the object should unambiguously inform the agent (and the child for that matter) about the 
correct location of the ball (Behne et al., 2005, 2012; Liszkowski et al., 2006, 2008) and has been shown to influence infants' expectations about an agents' actions (Song et al., 2008, Study 2). We expected that the infants should now expect the agent to search the ball at the current location (i.e., the cup) even if they did not understand the verbal features involved.

\section{Study 1b}

\subsection{Method}

\subsubsection{Participants}

Twenty-eight 18-month-old German-speaking children participated in this study. Children's mean age was 18 months; 10 days (range 17;17 - 19;10; 14 boys and 14 girls). Two additional children were tested but had to be excluded from the final sample due to experimenter error (i.e., the experimenter pointed at the wrong location, $n=1$ ) or because the child did not reach the familiarization-criterion ( $n=1$, see coding section Study 1a).

\subsubsection{Materials, design and procedure}

Materials and design were the same as in Study 1a with the exceptions that we 1) ran the Informative-Intervention Condition only, and 2) in the intervention phase, the assistant additionally pointed at the cup while verbally informing the agent about the ball's location. That is, during the experimental manipulation, the agent and the assistant simultaneously raised their heads and looked at each other $(1 \mathrm{sec})$. The assistant then said the German equivalent of "The ball is in the cup" ("der BALL IST IN DER TASse"; 2 sec; capital letters mark emphasized syllables). While uttering this sentence, she pointed at the cup by moving her hand with her index finger stretched above the cup and moving her hand a little bit closer towards the cup three times (for a total of three pointing instances). During the pause (1 sec), the assistant also looked towards the cup while still pointing at it and the agent followed her gaze. Then, both looked at each other again and the assistant repeated the sentence and pointing gesture $(2 \mathrm{sec})$. Both the agent and the assistant then looked back at the neutral point 
between both containers $(1 \mathrm{sec})$ and the assistant moved her hand back to the starting position. The assistant then reclined in her chair and closed the curtain in front of her. Then, the agent proceeded with the test phase.

\subsubsection{Coding and reliability.}

We used the same coding criteria as in Study 1a. An independent, blind coder coded a random sample of 6 children ( $21 \%$ of the sample). Inter-coder agreement was $90.6 \%$.

\subsection{Results and Discussion}

Preliminary analyses revealed that the children were very attentive throughout the study (with mean looking times at the actions performed in the initial scenes of all phases between $90 \%$ and $98 \%$ of the duration of these scenes, see Table 3 ).

\section{Table 3.}

Children's mean looking times at the initial scenes of each phase and mean durations of these scenes in seconds in Study 1b. Standard deviations in parentheses.

\begin{tabular}{lccc}
\hline & Looking time & Duration & Percent \\
\hline $1^{\text {st }}$ Familiarization Phase & $13.6(1.5)$ & $14.3(0.7)$ & $94.8(9.7)$ \\
\hline $2^{\text {nd }}$ Familiarization Phase & $14.7(0.9)$ & $15.1(0.8)$ & $97.5(5.3)$ \\
\hline $3^{\text {rd }}$ Familiarization Phase & $2.8(0.5)$ & $3.2(0.3)$ & $90.3(18.1)$ \\
\hline Belief Induction Phase & $12.1(0.7)$ & $12.4(0.7)$ & $98.3(4.0)$ \\
\hline Intervention Phase & $7.7(0.7)$ & $7.9(0.6)$ & $97.5(6.2)$ \\
\hline Test Phase & $2.5(0.4)$ & $2.7(0.3)$ & $94.8(15.1)$ \\
\hline
\end{tabular}

Children in both events looked equally long during the paused scenes of the familiarization phases, as revealed by an independent samples T-test on children's averaged looking times at the paused scenes of the familiarization phases $(t(26)=1.988, p=.065)$. A similar analysis of the children's looking times during the paused scene of the beliefinduction phase also revealed no significant effect $(t(26)=.491, p=.628)$.

Analyses of the test phase-paused scene. An independent samples T-test on children's looking time at the box event or the cup event in the paused scene of the test phase (see Table 4) revealed no significant difference $(t(26)=1.479, p=.161)$. 


\section{Table 4.}

Children's mean looking times (and standard deviations) in seconds at the test phase's paused scene of Study 1 across events.

\begin{tabular}{ccc}
\hline & Box Event & Cup Event \\
\hline $\begin{array}{c}\text { Informative-Intervention plus } \\
\text { Pointing Cond. }\end{array}$ & $8.5(4.7)$ & $6.6(1.0)$ \\
\hline
\end{tabular}

The results of this study indicate that 18-month-olds did not update their expectations about an agent's belief-based actions even when a pointing cue and the verbal informative intervention were provided in combination in order to unambigously inform the agent about the new location of the ball. This is in contrast to the findings by Song et al. (2008) who showed in two separate conditions that infants at the same age updated their expectations about the agent's belief-based actions when the assistant informed the agent about the object's location and also when she only pointed at the object's location.

So, why did we fail to replicate this original finding? One reason might be that, in contrast to Song et al. who tested North American infants, we tested German infants. This explanation does not seem reasonable since many previous studies demonstrated false-belief understanding in infants from this cultural background (D. Buttelmann et al., 2009; F. Buttelmann et al., 2015; Knudsen \& Liszkowski, 2012, 2013; Träuble et al., 2010). A more plausible reason might lie in methodological differences between the current studies and the original one. A close comparison of the procedures of Song et al. and the current studies 1a and $1 \mathrm{~b}$ reveals one (seemingly small) difference: We had left out inter-phase delays caused by a curtain in front of infants being closed for 10 seconds between all phases of the trial. One good reason for using such a delay could be that children need time to process the actions and the language involved in this task (Baillargeon et al., 2018), and the pauses caused by closing the curtain might have enabled children to do so in the original study. Thus, in Study 2, we reran Study 1 a with another sample of children - now having installed a curtain on the infants' 
side of the apparatus and closing it for 10 seconds between all phases of the trial.

\section{Study 2}

\subsection{Method}

\subsubsection{Participants}

Fifty-six 18-month-old German-speaking children participated in this study. The mean age of the children was 18 months; 12 days (range: 17;11 - 20;8, 26 boys and 30 girls). Five additional children were tested but had to be excluded from the final sample because of parental interference $(n=1)$, because of equipment failure $(n=1)$, because they did not reach the familiarization-criterion ( $n=1$, see coding section Study $1 \mathrm{a})$, or because they did not reach the minimum looking-time criterion in the test phase's paused scene $(n=2$, see coding section Study 1a).

\subsubsection{Materials, design and procedure}

Materials and design were the same as in Study 1a, with the exception that in Study 2 a curtain was attached to the apparatus right in front of the child. Children were presented with either the Informative-Intervention Delay Condition ${ }^{1}$ or the Uninformative-Intervention Delay Condition. The procedure of Study 2 was the same as in Study 1a with the exception that the curtain was closed in front of the child for 10 seconds after each paused scene of the three familiarization phases and the belief induction phase as well as after the intervention phase (which did not have a paused scene).

\subsubsection{Coding and reliability}

We used the same coding criteria as in Study 1a. An independent, blind coder coded a random sample of 10 children ( $18 \%$ of the sample). Inter-coder agreement was $81.5 \%$.

\subsection{Results and Discussion}

\footnotetext{
${ }^{1}$ Please note that the children reported here in the Informative-Intervention plus Curtain Condition are the same children that have been reported in Schulze and Buttelmann (2020) in the Social Context with Statement condition.
} 
Preliminary analyses revealed that the children were very attentive throughout the study (with mean looking time at the actions performed in the initial scenes of all phases between $91 \%$ and $99 \%$ of the duration of these scenes, see Table 5).

\section{Table 5.}

Children's mean looking times at the initial scenes of each phase and mean durations of these scenes in seconds in Study 2. Standard deviations in parentheses.

\begin{tabular}{lccc}
\hline & Looking Time & Duration & Percent \\
\hline $1^{\text {st }}$ Familiarization Phase & $13.8(1.1)$ & $14.3(0.8)$ & $96.9(5.7)$ \\
\hline $2^{\text {nd }}$ Familiarization Phase & $14.4(1.2)$ & $14.9(0.9)$ & $96.7(7.6)$ \\
\hline $3^{\text {rd }}$ Familiarization Phase & $2.9(0.5)$ & $3.0(0.2)$ & $97.0(14.5)$ \\
\hline Belief Induction Phase & $11.9(0.9)$ & $12.2(1.0)$ & $97.5(5.5)$ \\
\hline Intervention Phase & $7.8(0.7)$ & $7.9(0.4)$ & $98.0(6.6)$ \\
\hline Test Phase & $2.7(0.6)$ & $2.9(0.3)$ & $92.7(19.7)$ \\
\hline
\end{tabular}

To test whether the children in both conditions and events looked equally long during the paused scenes of the familiarization phases, we averaged the children's looking times at the paused scenes of the familiarization phases and ran a 2 (condition) x 2 (event) ANOVA. No effect was significant $\left(\right.$ all $F_{\mathrm{s}}(3,52)<1.722$, all $\left.p \mathrm{~s}>.20\right)$. A similar analysis of the children's looking times during the paused scene of the belief-induction phase also found no significant effects $($ all $F \mathrm{~s}(3,52)<2.397$, all $p \mathrm{~s}>.13)$.

Analyses of the test phase-paused scene. For statistical analyses the dependent variable was children's looking times at the box event or at the cup event in the paused scene of the test phase. A 2 (condition) x 2 (event) ANOVA revealed a significant main effect for event $\left(F(1,52)=17.065, p<.001, \eta^{2}=.247\right)$, but no main effect for condition $(F(1,52)=$ $1.061, p=.308)$ and no interaction $(F(1,52)=1.134, p=.292)$. Thus, infants in both conditions looked longer at the box event than at the cup event (see Table 6). 


\section{Table 6.}

Children's mean looking times (and standard deviations) in seconds at the test phase's paused scene of Study 2 across conditions and events.

\begin{tabular}{lcc}
\hline & Box Event & Cup Event \\
\hline Informative-Intervention Delay Cond. & $11.5(4.6)$ & $7.2(0.9)$ \\
\hline Uninformative-Intervention Delay Cond. & $9.8(3.3)$ & $7.2(2.1)$ \\
\hline
\end{tabular}

In this study, introducing a 10-second-delay after the intervention resulted in infants updating of their belief ascription. That such a delay may be beneficial for infants' performance makes sense given that the current task required a fair amount of processing: Not only were the infants required to track the actions of both the agent and the assistant, they also had to ascribe a belief to the agent. Later they needed to compute the utterance's linguistic material (lexical and syntactical processing) and the pragmatics of the communicative act (inferring what the assistant wanted to communicate). They then needed to revise their prior belief ascription and update their expectations regarding the agent's actions. Given these various aspects of action and communication processing, it seems likely that the infants were still trying to understand what was going in the trial at the time when the agent started searching the ball in Study 1a and 1b. In Study 2, however, closing the curtain right after the utterance may have given the infants the time necessary to process the actions and communication intervention. Only then were they able to update their representations about the agent's belief and form the resulting expectations about the agent's belief-based actions. Such processing demands seem to play an important role in a violation-ofexpectation paradigm using looking time as a measure for children's early false-belief understanding (cf., Scott \& Baillargeon, 2017; Baillargeon et al., 2018).

Importantly, in this study, we did not replicate the original finding in the Uninformative-Intervention condition. While in the original study infants did not update their expectations (they looked longer to the cup than to box event indicating that they still held a 
false-belief expectation), in the current study they showed a looking time pattern similar to that in the Informative-Intervention condition, indicating that they had updated their expectations. Thus, why did infants in the current study alter their belief ascription when they heared a so-called uniformative statement ("I like the cup")? First of all, theoretically, infants should do this given that communication always conveys its own premise of relevance (Grice, 1989; Sperber \& Wilson, 1995; Tomasello, 2008). That is, when something is said, the utterance should always be relevant to the hearer and bear some informative content since overt communication creates "not just expectations of cooperation but actual social norms, whose violation is unacceptable" (Tomasello, 2008, p. 92; see also Sperber \& Wilson, 1995). In other words, the agent (and possibly the participant) is forced to wonder why the assistant said she liked the cup in order to infer the relevance of this utterance in the current situation. Even infants are able to make such relevance inferences in nonverbal paradigms (Schulze \& Tomasello, 2015). Moreover, infants have been shown to consider exchanges of even nonverbal tone sequences or unfamiliar speech as a vehicle to transfer information (Martin et al., 2012; Tauzin \& Gergely, 2018; Vouloumanos et al., 2012).

It is thus rather unclear why the children in Song et al.'s (2008) study did not consider the preference-statement as a hint regarding the agent's search. One explanation for Song et al.'s findings could be that - despite our greatest efforts to follow the original procedure closely - there were still small differences between the current studies and that of Song and colleagues. One possible candidate for such a difference might be the intonation of the utterances. Intonation or prosody has been shown to affect communication comprehension reference resolution (e.g., reference resolution: Dahan et al., 2002; Grünloh et al., 2015; and implicature interpretation: Chevallier et al., 2008; Tomlinson Jr \& Bott, 2013). For our purposes, a sentence-wide prosody called 'Hutkontur' (hat pattern) is important: This pattern is used in German to mark contrastive information. That is, it signals that the utterance is to 
be processed as a chunk of new and important information (Braun, 2004; Mehlhorn, 2001; Steube, 2001; Wunderlich, 1991). The hat pattern prosody is commonly used for ,out of the blue sentences', such as, “(Guess what?) The ball is in the cup / I like the cup". Since the utterances in our current project were pronounced with the hat pattern prosody, this intonation might have signaled to the children that the assistant told the agent some new and important information that is contrastive to what she already knew. This additional processing signal was not present in the study by Song and colleagues where a more neutral intonation pattern was used (see Figure 2; personal communication with Renée Baillargeon). Future studies need to investigate which of these explanations might be most likely.

\section{Figure 2.}

Intonation patterns used in the original study (Song et al., 2008) and the current project. Whereas Song et al.'s study used a more neutral pattern (left), the current project used the contrastive hat pattern prosody (right).

\begin{tabular}{|cccc|} 
Neutral: & Ich mag die TASse & Contrastive: & Ich MAG DIE TASse. \\
& I like the CUP. & I LIKE THE CUP. \\
\hline
\end{tabular}

\section{General Discussion}

The aim of the current set of studies was to replicate the study by Song and colleagues (2008). Thus, using a violation-of-expectation paradigm, we tested whether 18-month-old children expected an agent to update her false-belief when the assistant communicated the new, actual location of a toy to the agent. In contrast to our expectations, Studies $1 \mathrm{a}$ and $1 \mathrm{~b}$ did not replicate the original finding. That is, in contrast to Song et al. (2008; see also Jin et al., 2019), infants did not have clear expectations regarding the agent's actions. Infants in Studies $1 \mathrm{a}$ and $1 \mathrm{~b}$ looked equally long at both events when the assistant had communicated the ball's current location verbally only or verbally and by pointing in combination. The 
results of Study 2, however, do indicate that infants updated their expectations about the agent's belief-based actions. That is, infants in this study looked longer at the box event than at the cup event when the agent had been informed about the ball having been located in the cup. In contrast to Studies 1a and 1b, in this study, we followed the design of the original study more closely, that is, we introduced a 10-second-delay between the trial's phases.

This set of studies thus emphasizes that direct replication attempts for single studies need to follow the original design and procedure as closely as possible. The current findings also demonstrate that a deviation from the procedure used in the original study (as it is common in conceptual replication attempts) might lead to a failure to replicate (see Baillargeon et al., 2018). Indeed, a close inspection of previous replication attempts of early infant ToM reveals that these studies often deviated from the studies they aimed to replicate in a number of aspects. The age of the participants or procedures were altered frequently compared to the original studies and sometimes, replication attempts of stand-alone tasks were part of ToM-batteries, making this task one of many tasks and providing infants with extended experience with the experimenters (Crivello \& Poulin-Dubois, 2018; Kulke \& Rakoczy, 2018). Whether or not this influences infants' results in these tasks needs to be addressed in further studies (for first empirical evidence that this might be the case see Crivello \& Poulin-Dubois, 2018). The findings from the current set of studies indicate that even seemingly small details (such as delays between a trials phases) have a tremendous effect on infants' performance in the task (e.g., compare Yott \& Poulin-Dubois, 2012; and Poulin-Dubois et al., 2013). Having said this, of course, strictly following the protocol of the original study does not necessarily result in a successful replication.

\section{Conclusion}

While conceptual replication attempts in Studies $1 \mathrm{a}$ and $1 \mathrm{~b}$ did not replicate findings on infants' use of communication to update their expectation of the agent's belief-based 
actions, the direct replication attempt in Study 2 did reveal the expected findings, at least partly. Infants updated their belief-based expectations regarding an agent's actions when they and the agent heard an informative statement about a toy's actual location (replicating Song et al., 2008; see also Jin et al., 2019). Moreover, infants also altered their expectations when they and the agent heard a so-called "uninformative" statement which was in fact a indirect communicative act about the toy's actual location (Grice, 1989; Sperber \& Wilson, 1995). Taken together, the current set of studies shows that replication attempts of single studies should follow the original study procedure as closely as possible - even in aspects that might be considered peripheral in the first place. 


\section{References}

Apperly, I. A., \& Butterfill, S. A. (2009). Do humans have two systems to track beliefs and belief-like states? Psychological Review, 116(4), 953-970. https://doi.org/10.1037/a0016923

Baillargeon, R., Buttelmann, D., \& Southgate, V. (2018). Invited commentary: Interpreting failed replications of early false-belief findings: Methodological and theoretical considerations. Cognitive Development, 46, 112-124. https://doi.org/10.1016/j.cogdev.2018.06.001

Behne, T., Carpenter, M., \& Tomasello, M. (2005). One-year-olds comprehend the communicative intentions behind gestures in a hiding game. Developmental Science, 8(6), 492-499. https://doi.org/10.1111/j.1467-7687.2005.00440.x

Behne, T., Liszkowski, U., Carpenter, M., \& Tomasello, M. (2012). Twelve-month-olds' comprehension and production of pointing. British Journal of Developmental Psychology, 30(3), 359-375. https://doi.org/10.1111/j.2044-835X.2011.02043.x

Braun, B. (2004). Phonetics and phonology of contrast marking in german: Issues for the prosody-semantics interface. Konvens, 29-36.

Buttelmann, D., Carpenter, M., \& Tomasello, M. (2009). Eighteen-month-old infants show false belief understanding in an active helping paradigm. Cognition, 112(2), 337-342. https://doi.org/10.1016/j.cognition.2009.05.006

Buttelmann, F., Suhrke, J., \& Buttelmann, D. (2015). What you get is what you believe: Eighteen-month-olds demonstrate belief understanding in an unexpected-identity task. Journal of Experimental Child Psychology, 131, 94-103. https://doi.org/10.1016/j.jecp.2014.11.009

Carruthers, P. (2013). Mindreading in infancy. Mind \& Language, 28(2), 141-172. https://doi.org/10.1111/mila.12014 
Chevallier, C., Noveck, I. A., Nazir, T., Bott, L., Lanzetti, V., \& Sperber, D. (2008). Making disjunctions exclusive. The Quarterly Journal of Experimental Psychology, 61(11), 1741-1760.

Crivello, C., \& Poulin-Dubois, D. (2018). Infants' false belief understanding: A nonreplication of the helping task. Cognitive Development, 46, 51-57. https://doi.org/10.1016/j.cogdev.2017.10.003

Dahan, D., Tanenhaus, M. K., \& Chambers, C. G. (2002). Accent and reference resolution in spoken-language comprehension. Journal of Memory and Language, 47(2), 292-314.

Grice, H. P. (1989). Studies in the way of words. Harvard University Press.

Grünloh, T., Lieven, E., \& Tomasello, M. (2015). Young children's intonational marking of new, given and contrastive referents. Language Learning and Development, 11(2), $95-127$.

Jin, K.-S., Kim, Y., Song, M., Kim, Y.-J., Lee, H., Lee, Y., Cha, M., \& Song, H.-J. (2019). Fourteen- to Eighteen-Month-Old Infants Use Explicit Linguistic Information to Update an Agent's False Belief. Frontiers in Psychology, 10. https://doi.org/10.3389/fpsyg.2019.02508

Kidd, D. C., \& Castano, E. (2017). Panero et al. (2016): Failure to replicate methods caused the failure to replicate results. Journal of Personality and Social Psychology, 112(3), e1-e4. https://doi.org/10.1037/pspa0000072

Knudsen, B., \& Liszkowski, U. (2012). Eighteen- and 24-month-old infants correct others in anticipation of action mistakes. Developmental Science, 15(1), 113-122. https://doi.org/10.1111/j.1467-7687.2011.01098.x

Knudsen, B., \& Liszkowski, U. (2013). One-Year-Olds Warn Others About Negative Action Outcomes. Journal of Cognition and Development, 14(3), 424-436. https://doi.org/10.1080/15248372.2012.689387 
Kulke, L., \& Rakoczy, H. (2018). Implicit Theory of Mind - An overview of current replications and non-replications. Data in Brief, 16, 101-104. https://doi.org/10.1016/j.dib.2017.11.016

Kulke, L., Reiß, M., Krist, H., \& Rakoczy, H. (2018). How robust are anticipatory looking measures of Theory of Mind? Replication attempts across the life span. Cognitive Development, 46, 97-111. https://doi.org/10.1016/j.cogdev.2017.09.001

Kulke, L., von Duhn, B., Schneider, D., \& Rakoczy, H. (2018). Is implicit theory of mind a real and robust phenomenon? Results from a systematic replication study. Psychological Science, 29(6), 888-900. https://doi.org/10.1177/0956797617747090

Liszkowski, U., Carpenter, M., Striano, T., \& Tomasello, M. (2006). 12- and 18-month-olds point to provide information for others. Journal of Cognition and Development, 7(2), 173-187. https://doi.org/10.1207/s15327647jcd0702_2

Liszkowski, U., Carpenter, M., \& Tomasello, M. (2008). Twelve-month-olds communicate helpfully and appropriately for knowledgeable and ignorant partners. Cognition, 108(3), 732-739. https://doi.org/10.1016/j.cognition.2008.06.013

Martin, A., Onishi, K. H., \& Vouloumanos, A. (2012). Understanding the abstract role of speech in communication at 12 months. Cognition, 123(1), 50-60. https://doi.org/10.1016/j.cognition.2011.12.003

Maxwell, S. E., Lau, M. Y., \& Howard, G. S. (2015). Is psychology suffering from a replication crisis? What does "failure to replicate" really mean? American Psychologist, 70(6), 487-498. https://doi.org/10.1037/a0039400

Mehlhorn, G. (2001). Produktion und Perzeption von Hutkonturen im Deutschen. Linguistische Arbeitsberichte, 77, 31-57.

Onishi, K. H., \& Baillargeon, R. (2005). Do 15-month-old infants understand false beliefs? Science, 308(5719), 255-258. https://doi.org/10.1126/science.1107621 
Poulin-Dubois, D., Polonia, A., \& Yott, J. (2013). Is false belief skin-deep? The agent's eye status influences infants' reasoning in belief-inducing situations. Journal of Cognition and Development, 14(1), 87-99. https://doi.org/10.1080/15248372.2011.608198

Poulin-Dubois, D., Rakoczy, H., Burnside, K., Crivello, C., Dörrenberg, S., Edwards, K., Krist, H., Kulke, L., Liszkowski, U., Low, J., Perner, J., Powell, L., Priewasser, B., Rafetseder, E., \& Ruffman, T. (2018). Do infants understand false beliefs? We don't know yet - A commentary on Baillargeon, Buttelmann and Southgate's commentary. Cognitive Development, 48, 302-315. https://doi.org/10.1016/j.cogdev.2018.09.005 Rubio-Fernández, P. (2018). Trying to discredit the Duplo task with a partial replication: Reply to Paulus and Kammermeier (2018). Cognitive Development, 48, 286-288. https://doi.org/10.1016/j.cogdev.2018.07.006

Schulze, C., \& Buttelmann, D. (2020). Infants understand that only in social interaction language updates an agent's false belief. https://doi.org/10.31234/osf.io/hmtvs Schulze, C., \& Tomasello, M. (2015). 18-month-olds comprehend indirect communicative acts. Cognition, 136, 91-98. https://doi.org/10.1016/j.cognition.2014.11.036

Scott, R. M., \& Baillargeon, R. (2017). Early false-belief understanding. Trends in Cognitive Sciences, 21(4), 237-249. https://doi.org/10.1016/j.tics.2017.01.012

Song, H., Onishi, K. H., Baillargeon, R., \& Fisher, C. (2008). Can an agent's false belief be corrected by an appropriate communication? Psychological reasoning in 18-monthold infants. Cognition, 109(3), 295-315. https://doi.org/10.1016/j.cognition.2008.08.008

Southgate, V., Senju, A., \& Csibra, G. (2007). Action Anticipation Through Attribution of False Belief by 2-Year-Olds. Psychological Science, 18(7), 587-592. https://doi.org/10.1111/j.1467-9280.2007.01944.x 
Sperber, D., \& Wilson, D. (1995). Relevance: Communication and cognition (2nd ed.). Blackwell Publishing.

Steube, A. (2001). Grammatik und Pragmatik von Hutkonturen. Linguistische Arbeitsberichte, 77, 7-30.

Tauzin, T., \& Gergely, G. (2018). Communicative mind-reading in preverbal infants. Scientific Reports, 8(1), 9534.

Tomasello, M. (2008). Origins of human communication. MIT Press.

Tomlinson Jr, J. M., \& Bott, L. (2013). How intonation contrains pragmatic inference. Proceedings of the Annual Meeting of the Cognitive Science Society, 35.

Träuble, B., Marinović, V., \& Pauen, S. (2010). Early Theory of Mind Competencies: Do Infants Understand Others' Beliefs? Infancy, 15(4), 434-444. https://doi.org/10.1111/j.1532-7078.2009.00025.x

Vouloumanos, A., Onishi, K. H., \& Pogue, A. (2012). Twelve-month-old infants recognize that speech can communicate unobservable intentions. Proceedings of the National Academy of Sciences, 109(32), 12933-12937.

https://doi.org/10.1073/pnas.1121057109

Wunderlich, D. (1991). Intonation and contrast. Journal of Semantics, 8(3), 239-251.

Yott, J., \& Poulin-Dubois, D. (2012). Breaking the rules: Do infants have a true understanding of false belief? British Journal of Developmental Psychology, 30(1), 156-171. https://doi.org/10.1111/j.2044-835X.2011.02060.x 